\title{
Microstrip Dual Mode Multi-bandpass Filters Based on Tree Fractal Slotted Resonator for Wireless Communication
}

\author{
Manju Bhaskar', Thomaskutty Mathew ${ }^{2}$ \\ ${ }^{1,2}$ Department of Electronics, School of Technology and Applied Sciences \\ Mahatma Gandhi University Regional Center, Kerala, India
}

\begin{abstract}
Article Info
Article history:

Keywords:

Bandpass

Tree fractal

Modes

Patch Filter

Resonators
\end{abstract}

Received Feb 20, 2019

Revised Apr 30, 2019

Accepted Aug 23, 2019

\begin{abstract}
Dual mode microstrip multi-bandpass filter is proposed with tree fractal slot on a square patch resonator. The tree fractal slotted resonators are generated from conventional square patch using an iterative tree fractal generator method. A single square patch is used for realizing both dual and tri-bandpass filters exploiting the dominant, higher order and its corresponding degenerate resonant modes by the tree fractal iteration on the diagonal unequal slots on the square patch. The resonant peaks, transmission zeros and bandwidth of the pass bands can be tuned by varying the length and width of the fractal slot. By optimizing various parameters dual mode dual and tri-band pass filters are simulated, fabricated and measured. The proposed filter finds application in wireless communication devices and falls in the bands of GSM, WLAN, Bluetooth, Zigbee, WiMax and WiFi.
\end{abstract}

Copyright $(2019$ Institute of Advanced Engineering and Science. All rights reserved.

\section{Corresponding Author:}

Manju Bhaskar,

School of Technology and Applied Sciences,

Mahatma Gandhi University Regional Center,

Edappally, Kochi, India.

Email: sudheeshmanju@gmail.com

\section{INTRODUCTION}

Wireless communication applications necessitate the deployment of transceivers in radio frequency range with enhanced performance, compactness, low weight, and multiband characteristics. Microwave filters are inevitable part of radio frequency transceivers which play a key role in effectively transmitting the desired signals in certain pass-band regions while attenuating all the undesired signals in the remaining regions. The major techniques used in the design of microwave filters are presented by Ralph Levy et al in [1]. The recent advances of novel materials and fabrication technologies have simulated the rapid development and use of microstrip and other filters [2]. R.N Baral et al reported several techniques and initiatives made for improved response and enhanced performance of microwave planar filters [3].

A patch resonator is characterized by infinite number of resonant frequencies corresponding to different modes [4]. Dual mode multiband filters can be realized by coupling the resonant and its corresponding degenerate modes. Usually the degenerate modes of the square resonator are excited and coupled using orthogonal feed lines and in addition to any of the methods like crossed slots, shorting pin, addition of patches and corner patch cuts [4].

Various dual mode bandpass microstrip filters with orthogonal feeding and unequal diagonal cross slots acting as perturbation element for the patch, have been reported in [5-7]. In [8,9] the detailed study of the coupling between degenerate modes are well explained for a microstrip loop resonator. S.Shen et al presented how compactness is achieved by the increased path length created by the slots over the patch and reducing the resonant frequency to a lower side in [10]. A dual band filter with size reduction using cross slotted patch and square etched slot for a dual mode bandpass filter is reported by Min-Hang Weng et al in [11]. In [12], Kenneth S. K et al realized a dual-band bandpass filter by coupling each of the shunt resonators with an additional identical shunt resonator through a J-inverter. In various systems stepped impedance filters are reported for dual band applications [13-14]. Dual-band bandpass filter using stub-loaded resonator in which even-mode resonant frequency can be 
conveniently tuned is explained in [15]. Open loop ring resonator and a folded coupled line resonators are also alternatives for bandpass filter design [16].

Fractals are geometries having self-similarity and space filling properties with non-integer dimension. Fractal geometry is generated in an iterative fashion, leading to self-structure. These unique properties combined with electromagnetic theory finds applications in fractal electrodynamics [17]. Self-similarity property of fractal geometries can be successfully applied to the design of multi-band filters while the space-filling property can be utilized for miniaturization. In fractal structures each sub-section has the characteristics of the whole structure in a smaller scale [18]. A dual mode T- square fractal dual band bandpass filter which uses shorting pin as perturbation element is reported in [19].Jian-Kang Xiao et al reported a single trapezoidal patch bandpass filter incorporating fractal defection slots for realizing a single wide band, dual-band and tri-band dual mode behavior [20]. A left handed multiband metamaterial with tree fractal structure is presented by Xu He-Xiu et al in [21]. Dual mode compact bandpass filters based on patch, ring and semi fractal CSRR structures are reported in [22-27].

This paper presents a tree fractal slotted square patch resonator exciting the dominant and higher order modes. Tree fractal is a simple fractal structure which provides flexibility in tuning the resonant peaks, transmission zeros and bandwidth of the pass bands of the filter designed. Not all slotted fractal structures on a patch excites higher order and its degenerate modes but it is easily achieved by increasing the iteration levels of tree fractal slot on the same patch. Dual and tri-bandpass responses are generated by increasing the fractal iteration on the same structure without additional coupling or added structures as used for realizing multiband filter. Each resonator act as doubly tuned resonant circuit and the number of resonators needed for designing an nth order filter is reduced by half.

\section{RESEARCH METHOD}

\subsection{Tree Fractal Generation Process}

The schematics showing the generation process of the tree fractal structure is given in Figure 1.The procedure to create a tree fractal starts off with a line of length $L$ and width $d$ as in Figure 1 (a) which acts as the generator. At the first level of iteration, the length $\mathrm{L}$ is divided into three equal segments. A line segment with one third of the length $\mathrm{L}$ is introduced perpendicular to the initial line $\mathrm{L}$ at the first point of division and also a segment with the same length is positioned at the second point of division, again perpendicular to the initial line L but in the opposite direction. Fig 1(b) depicts the structure after first iteration. This forms the basic step for the formation of the tree fractal. Fractal dimension D is given by

$$
D=\frac{\log (N)}{\log (r)}
$$

where $\mathrm{N}$ is the number of self-similar line segments after each iteration level and $\mathrm{r}$ is the scaling factor [28-29]. After the first level iteration there are five equal line segments. In the consecutive iteration process, each segment is considered as the initial line segment and following the same procedure will attain the second iterated structure as in Fig 1(c).Further the third level iteration results in the fractal structure as shown in Fig 1 (d).

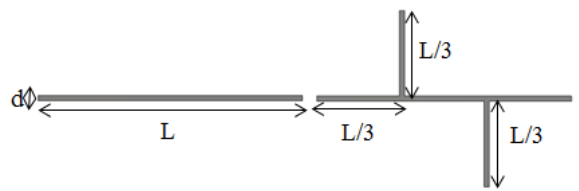

(a)

(b)

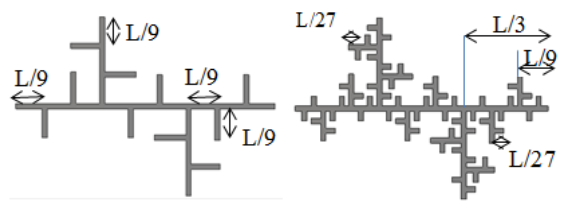

(c)

(d)

Figure 1. Schematics of the formation of the tree fractal geometry (a) generator

(b) first level iteration (c) second level iteration (d) third level iteration

\subsection{Dual Mode Square Patch Resonator}

The orthogonal feed lines along with unequal diagonal slots with length $\mathrm{c}$ and $\mathrm{g}$ and width of the slots, $\mathrm{d}$ $\mathrm{mm}$ will perturb the symmetry of a square patch and excite degenerate modes $[5,10]$. The perturbation to the symmetry of the patch resonator splits the resonant frequency into two close frequencies. The field distributions of the dominant and its degenerate mode are no longer orthogonal and the modes couple each other [19]. Such a conventional dual mode square patch filter is given in Figure 2(a)[5]. Fig 2(b) gives the coupling structure for the

Microstrip dual mode multi-bandpass filters based on tree fractal slotted resonator ....... (Manju Bhaskar et al) 
conventional dual mode filter in which $\mathrm{R}$ and $\mathrm{R}$ " denotes the resonators corresponding to the dominant and its degenerate mode respectively.

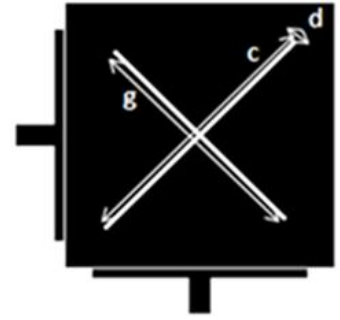

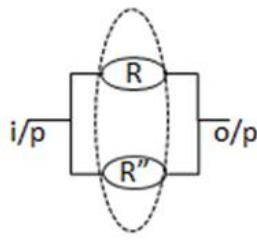

(b)

Figure 2 (a) Layout of the conventional dual mode filter (b) Coupling structure for the conventional dual mode filter.

The electromagnetic fields in the square patch resonator can be explained in terms of $\mathrm{TM}^{\mathrm{Z}}{ }_{\mathrm{m} n}$ modes [4] with $\mathrm{Z}$ perpendicular to the ground plane. The resonant frequency of the cavity is given as

$$
f m n_{0}=\frac{c}{2 \Pi \sqrt{\mu_{r} \varepsilon_{r}}} \sqrt{\left(\frac{m \pi}{a}\right)^{2}+\left(\frac{n \pi}{b}\right)^{2}}
$$

where $\mathrm{a}$ and $\mathrm{b}$ are the sides of the square patch resonator. $\varepsilon_{\mathrm{r}}$ is the dielectric constant of the substrate used. Square patch resonator supports fundamental degenerate modes $\mathrm{TM}_{100}$ and $\mathrm{TM}_{010}$ and an infinite number of higher order modes. For a square geometry every mode is degenerate, having same resonant frequencies [4].

The simulated s-parameter characteristics for the filter with varying $\mathrm{g}$ and $\mathrm{d}$ values are shown in Figures from 3(a-c). The depth of the mode splitting increases as difference between the length of two slots increases [5]. As the slot width $d$ increases the resonant frequency shifts to the lower end. The increased length seen by the electric current causes a leftward shift or reduction in the resonant frequency. Figure 3(d) gives the simulated surface current distribution of the conventional dual mode filter at $2.3 \mathrm{GHz}$. The current density is equal and opposite throughout both vertical and horizontal directions [5].

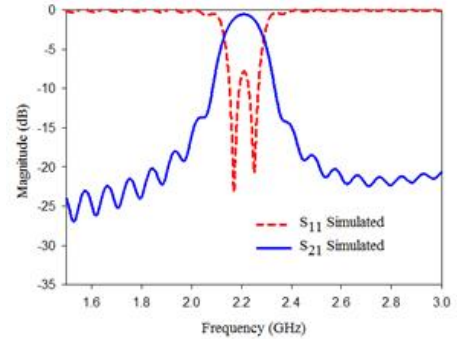

(a)

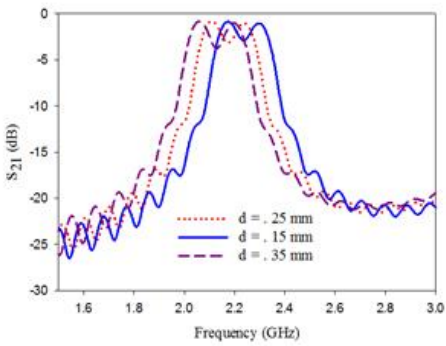

(c)

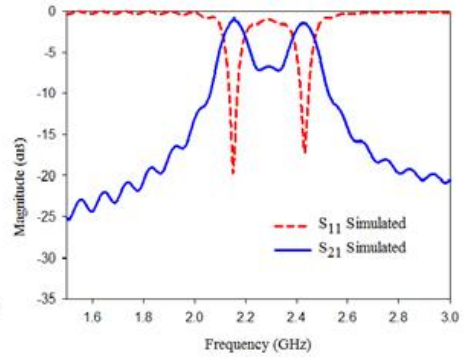

(b)

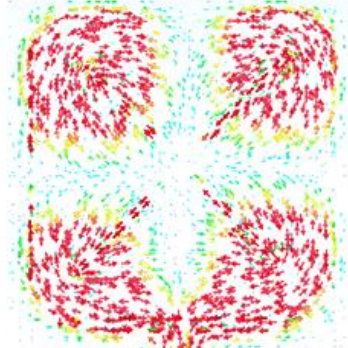

(d)

Figure 3. (a) Simulated s-parameter plot for $\mathrm{c}=30 \mathrm{~mm} \mathrm{~g}=28 \mathrm{~mm}$ and $\mathrm{d}=0.2 \mathrm{~mm}$ (b) Simulated S parameter plot for $\mathrm{c}=30 \mathrm{~mm}$ and $\mathrm{g}=25 \mathrm{~mm}$ and $\mathrm{d}=0.2 \mathrm{~mm}$ (c) Simulated $\mathrm{S}_{21}$ plot for $\mathrm{d}=0.15 \mathrm{~mm}, 0.25 \mathrm{~mm}, 0.35 \mathrm{~mm}$

(d) Surface current distribution of the conventional dual mode filter at $2.3 \mathrm{GHz}$.

\section{RESULTS AND DISCUSSION}

\subsection{Tree Fractal Dual Mode Dual Bandpass Filter}

Tree fractal iteration performing on the diagonal slots, excites and couples the higher order and its corresponding degenerate modes. First level tree fractal iteration was introduced only on slot c. Slot $\mathrm{g}$ is placed diagonal to slot $\mathrm{c}$. The proposed bandpass filter for dual band operation is depicted in Figure 4(a) and the coupling 
structure is plotted in Figure 4(b). The ith resonator which is corresponding to the $i^{\text {th }}$ mode is denoted by $R_{i}$, and $\mathrm{i}^{\text {th }}$ degenerate mode is $\mathrm{R}_{\mathrm{i}}$ " for $\mathrm{i}=1,2$. The first pass band is introduced by the coupling of the resonators $\mathrm{R}_{1}$ and $\mathrm{R}_{1}$ " and the second pass band is introduced by the coupling of the resonators $\mathrm{R}_{2}$ and $\mathrm{R}_{2}$ ".

From the $S_{11}$ and $S_{21}$ simulated results shown in Figure 5(a) and 5(b), it is evident that the dominant, first higher order and their corresponding degenerate modes are excited for g values $28 \mathrm{~mm}$ and $25 \mathrm{~mm}$ with slot $\mathrm{c}$ length of $30 \mathrm{~mm}$. As the difference in the length of $\mathrm{c}$ and g slots increases, the perturbation to the symmetry of patch increases allowing a wider split between the resonant peaks of the coupled modes. Measured $\mathrm{S}$ parameters can be observed from Figure $5(\mathrm{c}-\mathrm{d})$. Table 1 gives the performance of the dual band filters. To verify the design all the proposed filters are fabricated on RT/Duroid 5880 substrate having a relative dielectric constant of 2.2. The surface current distribution for the filter at $4.2 \mathrm{GHz}$ is given in Figure 6(a). The current flow indicates that first level tree fractal iteration introduces an increase in the electrical length of the current path compared to Figure 3(d).The photograph of the fabricated dual band filter is shown in figure 6(b).

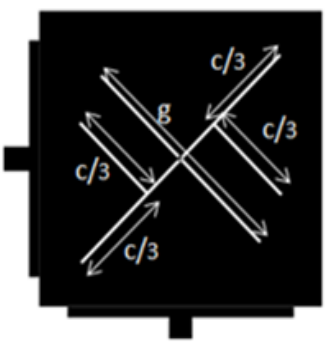

(a)

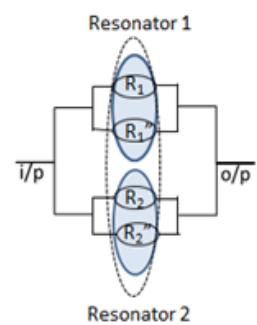

(b)

Figure 4(a)Layout of the dual mode dual bandpass filter (b)Coupling structure of the dual mode dual bandpass filter.

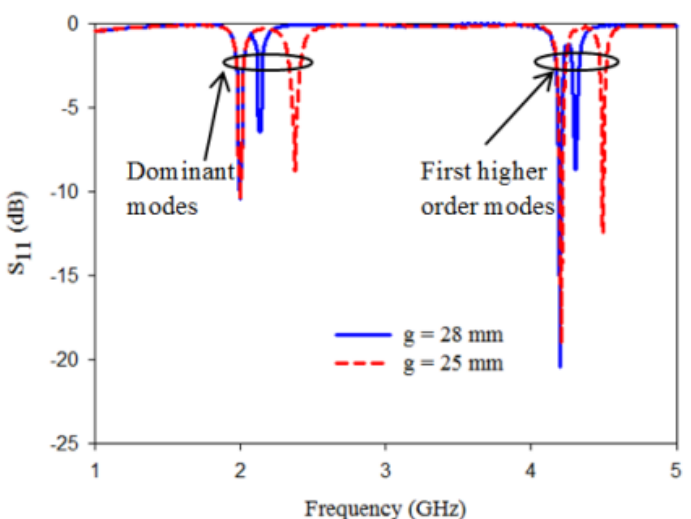

(a)

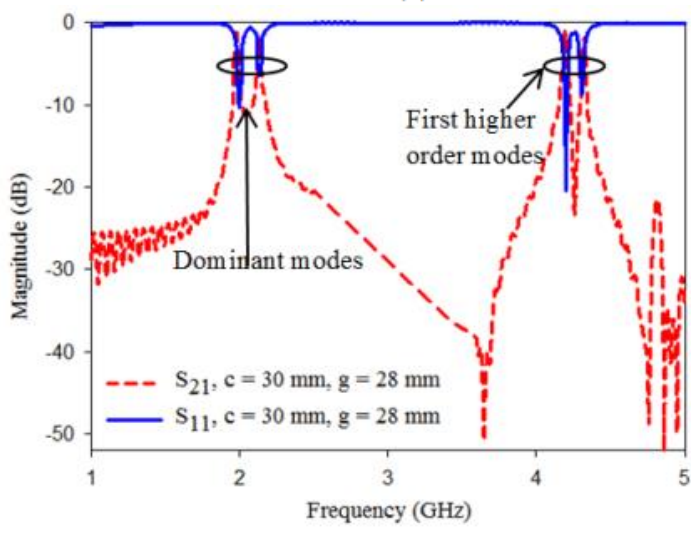

(c)

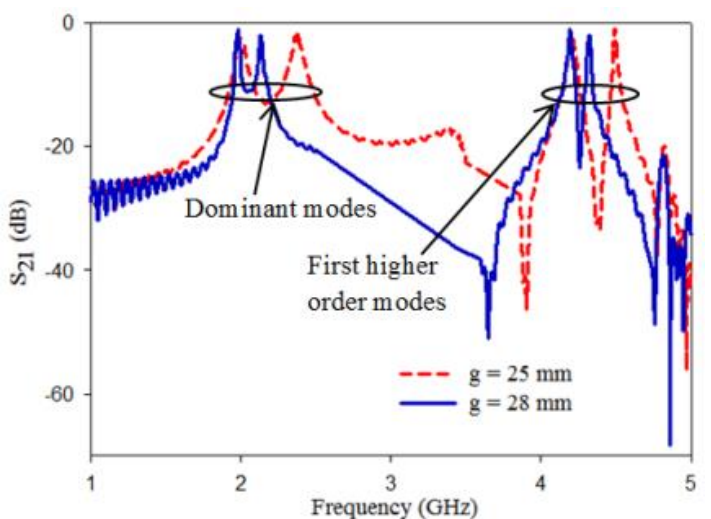

(b)

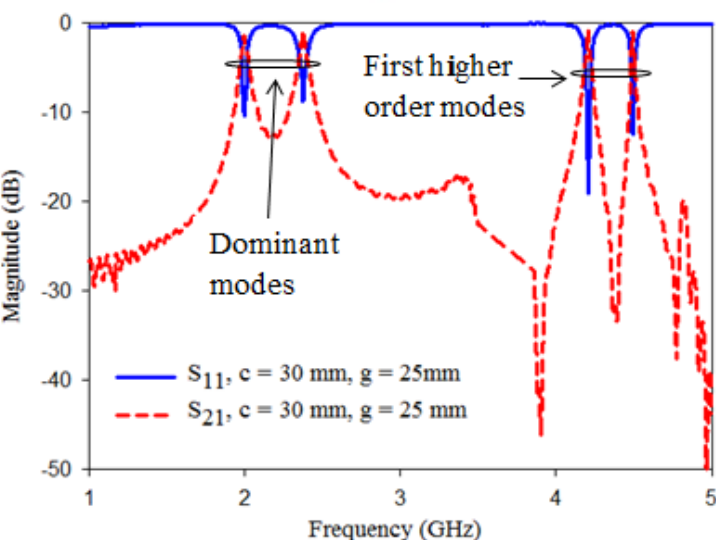

(d)

Figure 5(a) Simulated $S_{11}$ plot of the filter for varying values of $g$ (b) Simulated $S_{21}$ plot of the filter for varying values of $g$ (c) Measured $S$ parameters for the filter with $c=30 \mathrm{~mm}, \mathrm{~g}=28 \mathrm{~mm}, \mathrm{~d}=0.2 \mathrm{~mm}(\mathrm{~d})$ Measured $\mathrm{S}$ parameters for the filter with $\mathrm{c}=30 \mathrm{~mm}, \mathrm{~g}=25 \mathrm{~mm}, \mathrm{~d}=0.2 \mathrm{~mm}$. 
Table 1. Measured parameters for the dual band filters.

\begin{tabular}{rccccc}
\hline $\begin{array}{c}\text { Performance } \\
\text { Parameters }\end{array}$ & $\begin{array}{c}\text { Transmission } \\
\text { Bands }(\mathrm{GHz})\end{array}$ & $\begin{array}{c}\text { Resonances } \\
(\mathrm{GHz})\end{array}$ & $\begin{array}{c}\text { Insertion } \\
\text { Loss }(\mathrm{dB})\end{array}$ & $\begin{array}{c}\text { Retum Loss } \\
(\mathrm{dB})\end{array}$ & $\begin{array}{c}\text { Transmission Zeros } \\
\text { between pass bands } \\
(\mathrm{GHz})\end{array}$ \\
\hline Filter1- $\mathrm{c}=30 \mathrm{~mm}$ & Band 1: $1.97-2.14$ & $1.97,2.23$ & $0.71,1.20$ & $10.49,9.01$ & Band 1 \& 2:3.64 \\
$\mathrm{g}=28 \mathrm{~mm}$ & Band 2: $4.18-4.32$ & $4.19,4.30$ & $0.60,1.32$ & $20.56,9.73$ & \\
$\mathrm{~d}=0.2 \mathrm{~mm}$ & & & & & \\
& & & & & \\
Filter2- $\mathrm{c}=30 \mathrm{~mm}$ & Band 1: $1.97-2.44$ & $1.99,2.40$ & $0.86,1.02$ & $10.55,9.08$ & Band 1 \& 2:3.89 \\
$\mathrm{g}=25 \mathrm{~mm}$ & Band 2:4.17-4.51 & $4.20,4.49$ & $0.71,0.87$ & $19.25,12.32$ & \\
$\mathrm{~d}=0.2 \mathrm{~mm}$ & & & & & \\
\hline
\end{tabular}

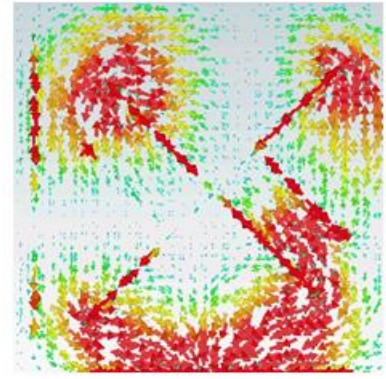

(a)

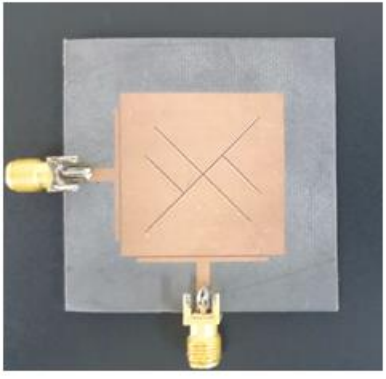

(b)

Figure 6(a) Surface current distributions of the dual band filter at $4.2 \mathrm{GHz}$ (b) Prototype of the dual band filter.

\subsection{Dual Mode Tri-Band Bandpass Filter}

In the tri band filter, first level tree fractal iteration is carried out for both the slots $\mathrm{c}$ and $\mathrm{g}$. The structure of the filter is given in Figure 7(a) and the coupling structure is shown in Figure 7(b). From the $\mathrm{S}_{11}$ and $\mathrm{S}_{21}$ simulation plots in Figure 8(a) and 8(b), the dominant, first and second higher order mode splits can be observed for $\mathrm{c}=30 \mathrm{~mm}$ and for varying $\mathrm{g}$ values of $28 \mathrm{~mm}$ and $25 \mathrm{~mm}$ with slot width $\mathrm{d}=0.2 \mathrm{~mm}$. The fractal extension of slot $\mathrm{g}$ and $\mathrm{c}$ exploits the higher order modes. The measured magnitude responses for length $\mathrm{c}=30 \mathrm{~mm}, \mathrm{~d}=$ $0.2 \mathrm{~mm}$ and for g values $28 \mathrm{~mm}, 25 \mathrm{~mm}$ is given in Figure 8(c) and 8(d) respectively. By optimizing the filter for the required bands for WLAN, WiMAX, Bluetooth and Zigbee, the filter parameters are set for $\mathrm{c}=30 \mathrm{~mm}$, $\mathrm{g}=22 \mathrm{~mm}$ and $\mathrm{d}=0.2 \mathrm{~mm}$ and measured magnitudes are given in figure $8(\mathrm{e})$.

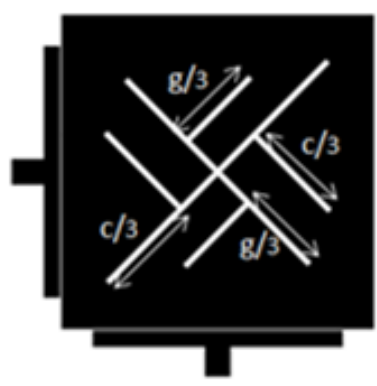

(a)

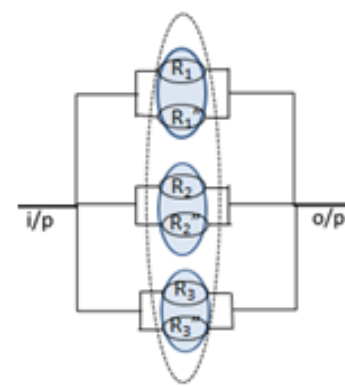

(b)

Figure7 (a) Layout of the first level iterated tri-band bandpass filter (b) Coupling structure of the tri-band filter. 

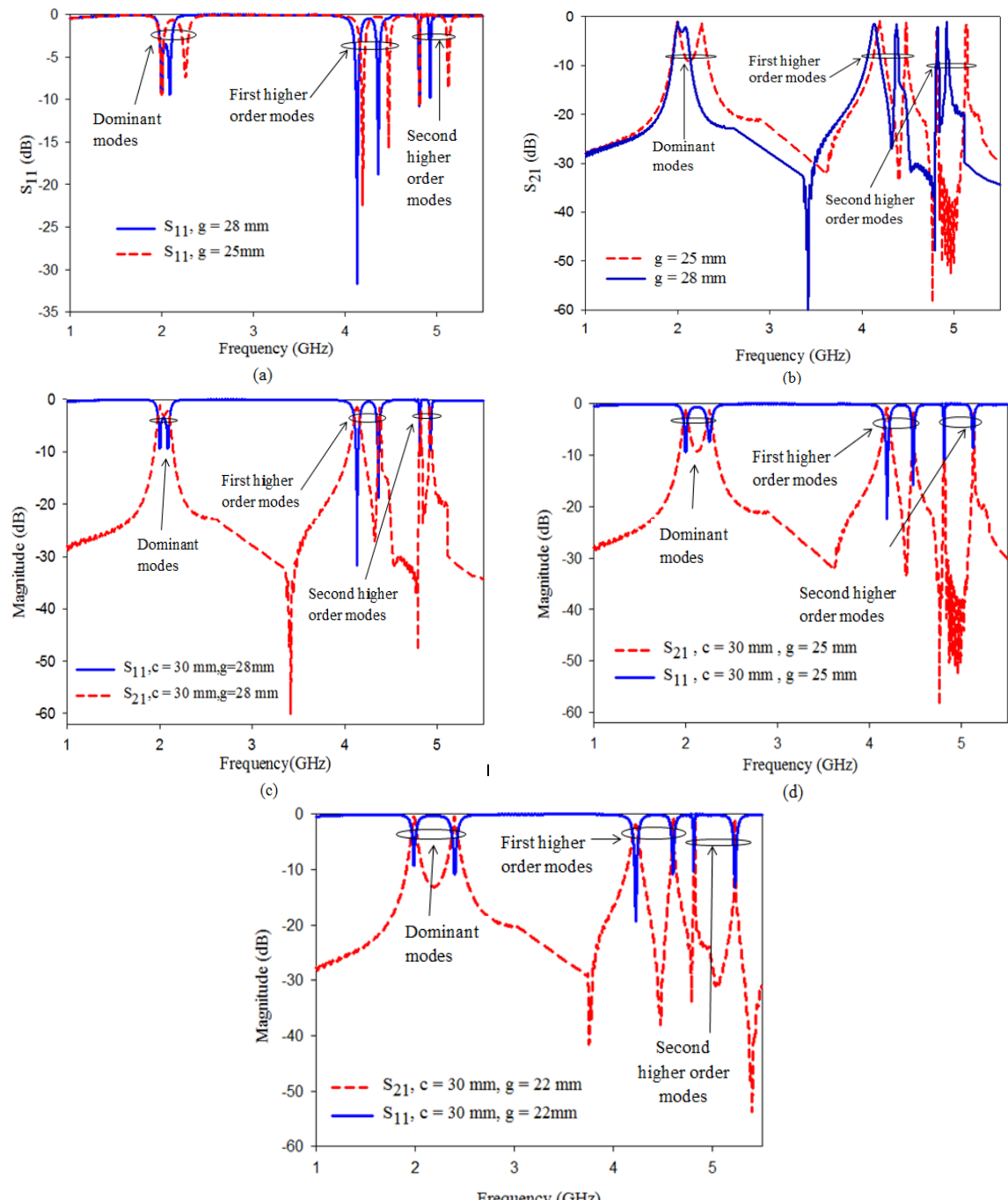

(e)

Figure 8(a) Simulated $S_{11}$ plot of the filter for varying values of $g(b)$ Simulated $S_{21}$ plot of the filter for varying values of $g$ (c) Measured S parameters for the filter with $g=28 \mathrm{~mm}$ (d) Measured $\mathrm{S}$ parameters for the filter with $\mathrm{g}=25 \mathrm{~mm}(\mathrm{e})$ Measured S parameters for the filter with $\mathrm{g}=22 \mathrm{~mm}$.

Table 2. Performance of the tri-band filters.

\begin{tabular}{|c|c|c|c|c|c|}
\hline $\begin{array}{l}\text { Performance } \\
\text { Parameters }\end{array}$ & $\begin{array}{l}\text { Transmission } \\
\text { Bands (GHz) }\end{array}$ & $\begin{array}{l}\text { Resonances } \\
(\mathrm{GHz})\end{array}$ & $\begin{array}{l}\text { Insertion } \\
\text { Loss (dB) }\end{array}$ & $\begin{array}{l}\text { Retum Loss } \\
\text { (dB) }\end{array}$ & $\begin{array}{c}\text { Transmission Zeros } \\
\text { between pass bands } \\
(\mathrm{GHz})\end{array}$ \\
\hline Filter $1-\mathrm{c}=30 \mathrm{~mm}$ & Band 1: $1.97-2.10$ & $1.98,2.08$ & $0.80,0.81$ & $9.89,9.86$ & Band $1 \& 2: 3.04$ \\
\hline $\begin{array}{l}\mathrm{g}=28 \mathrm{~mm} \\
\mathrm{~d}=0.2 \mathrm{~mm}\end{array}$ & $\begin{array}{l}\text { Band 2: } 4.09-4.38 \\
\text { Band 3: } 4.80-4.94\end{array}$ & $\begin{array}{l}4.13,4.36 \\
4.82,4.92\end{array}$ & $\begin{array}{l}1.02,1.10 \\
1.32,1.08\end{array}$ & $\begin{array}{c}31.9,19.03 \\
11.01,10.20\end{array}$ & Band $2 \& 3: 4.78$ \\
\hline Filter $\begin{aligned} 2-\mathrm{c} & =30 \mathrm{~mm} \\
\mathrm{~g} & =25 \mathrm{~mm} \\
\mathrm{~d} & =0.2 \mathrm{~mm}\end{aligned}$ & $\begin{array}{l}\text { Band 1: } 1.97-2.27 \\
\text { Band 2: } 4.10-4.48 \\
\text { Band 3: } 4.79-5.14\end{array}$ & $\begin{array}{l}1.99,2.25 \\
4.19,4.41 \\
4.80,5.11\end{array}$ & $\begin{array}{l}0.90,0.98 \\
0.54,1.12 \\
0.82,0.92\end{array}$ & $\begin{array}{c}10.01,9.03 \\
22.2,15.85 \\
10.7,9.56\end{array}$ & $\begin{array}{l}\text { Band } 1 \& 2: 3.64 \\
\text { Band } 2 \& 3: 4.77\end{array}$ \\
\hline Filter $\begin{aligned} 3-\mathrm{c} & =30 \mathrm{~mm} \\
\mathrm{~g} & =22 \mathrm{~mm} \\
\mathrm{~d} & =0.2 \mathrm{~mm}\end{aligned}$ & $\begin{array}{l}\text { Band 1: } 1.97-2.43 \\
\text { Band 2: } 4.18-4.62 \\
\text { Band 3: } 4.80-5.38\end{array}$ & $\begin{array}{l}1.98,2.41 \\
4.22,4.61 \\
4.81,5.30\end{array}$ & $\begin{array}{l}0.33,0.33 \\
1.01,0.69 \\
0.93 .0 .86\end{array}$ & $\begin{array}{c}10.01,10.9 \\
19.2,10.9 \\
10.7,13.8\end{array}$ & $\begin{array}{l}\text { Band } 1 \& 2: 3.76 \\
\text { Band } 2 \& 3: 4.78\end{array}$ \\
\hline
\end{tabular}


The measured values for the parameters of the tri-band filters with varying g values are given in Table 2. From the tabulated measurements and the plots it is evident that for each transmission band there is a pair of resonances. The bandwidth of each transmission band, location of transmission zeros between the pass bands, insertion and return losses at three pass bands vary according to the parameter $\mathrm{g}$. All the filters possess good insertion losses better than $1.32 \mathrm{~dB}$ and good return losses. Figure 9 shows the relation between the resonant frequency and the length of slot $\mathrm{g}$. The plot reveals that for the decrease in the length of slot $\mathrm{g}$ from $28 \mathrm{~mm}$ to 22 $\mathrm{mm}$, the coupling between the modes increases and we can observe a larger splitting between the resonant peaks. As the value of $g$ decreases, the difference between length $\mathrm{c}$ and $\mathrm{g}$ increases, and correspondingly the depth of perturbation to symmetry of the filter structure increases causing modes to split apart further. Surface current distribution of the first level iterated filter at $4.9 \mathrm{GHz}$ is as shown in figure 10(a) and the photograph of the filter is given in 10(b). The layout of the second and third level iterations on the slots, results in tri-band filter structures as shown in Figure 11 (a) and (b) respectively.

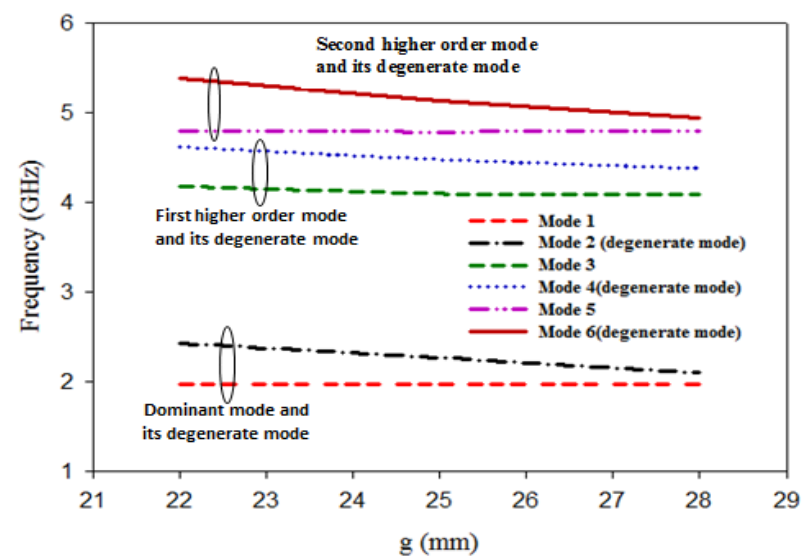

Figure 9. Relationship between resonant frequency and parameter $\mathrm{g}$ for $\mathrm{c}=30 \mathrm{~mm}$ and $\mathrm{d}=0.2 \mathrm{~mm}$.

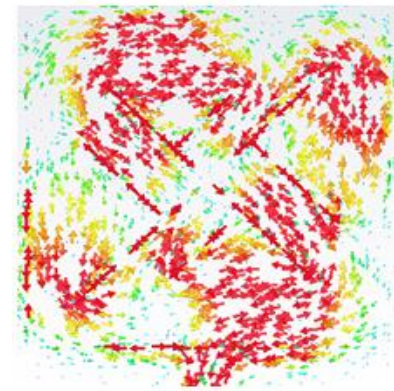

(a)

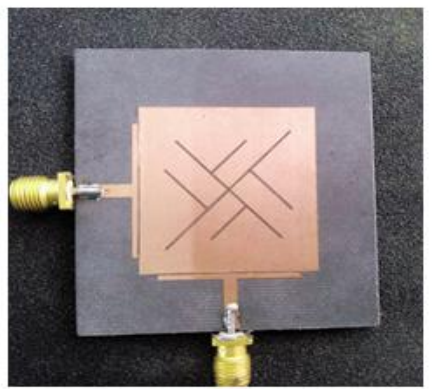

(b)

Figure 10 (a) Surface current distributions of first level iterated tri-band filter at $4.9 \mathrm{GHz}$

(b) Prototype of the first level iterated tri-band filter.

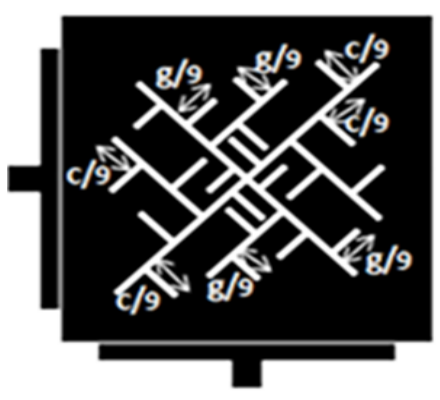

(a)

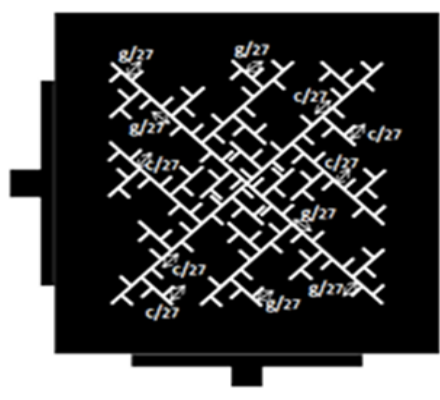

(b)

Figure 11. Layout of the tri-band dual mode bandpass filter (a) Second level iteration (b) third level iteration

The magnitude responses for the second and third level iterated tree fractal tri-band filters, optimized for frequency bands suitable for wireless communication applications are shown in Figure 12(a) and (b) 
respectively. From figure 12(a), the three pass bands are of $340 \mathrm{MHz}$ having fractional bandwith $17.2 \%$ centered at $1.97 \mathrm{GHz}, 100 \mathrm{MHz}$ about $2.6 \%$ centered at $3.8 \mathrm{GHz}$ and $290 \mathrm{MHz}$ about $6.4 \%$ centered at $4.6 \mathrm{GHz}$. The frequency, at which the excited modes resonates shift further to the lower frequency side as the area of the tree fractal slot increases further for the second iteration level compared to first level. As shown in Figure 12(b), the $\mathrm{S}_{21}$ response gives three considerable pass band response of $230 \mathrm{MHz}$ about $12.2 \%$ centered at $1.87 \mathrm{GHz}, 190$ $\mathrm{MHz}$ about $5.3 \%$ centered at $3.5 \mathrm{GHz}$ and $210 \mathrm{MHz}$ about $4.46 \%$ centered at $4.7 \mathrm{GHz}$. Insertion losses are better than $.57 \mathrm{~dB}$ and return losses greater than $10 \mathrm{~dB}$ for both the filters. Increasing the level of iteration and varying the $g$ value results in tri-band filters with controllable bandwidth and passband resonant peaks. Figure 13(a) depicts the surface current distributions for the second level iterated tri-band tree fractal filter at $4.6 \mathrm{GHz}$ and 13(b) shows the second level iterated tri-band filter prototype. Figure 14(a) shows the surface current distributions for the third level iterated tri-band tree fractal filter at $4.7 \mathrm{GHz}$ and $14(\mathrm{~b})$ shows the photograph of the corresponding filter prototype.

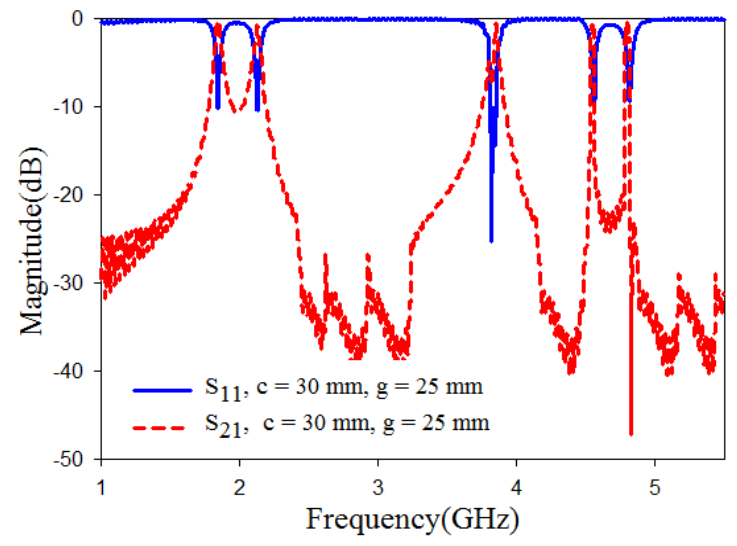

(a)

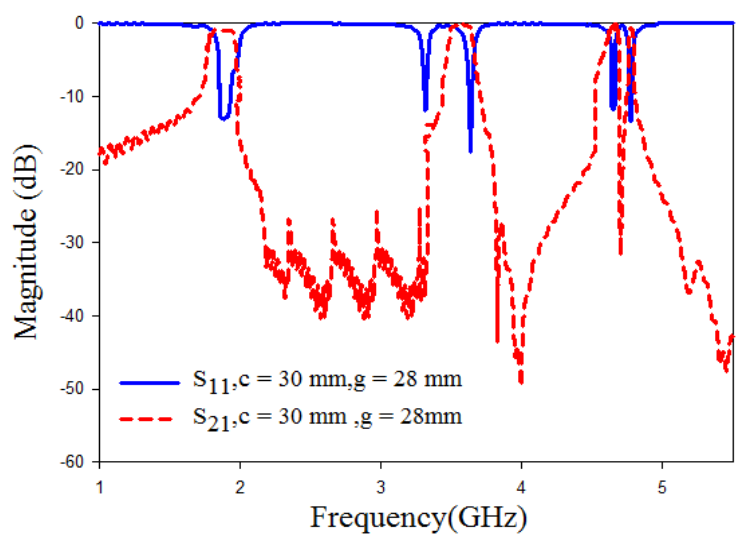

(b)

Figure 12 (a)Measured $\mathrm{S}$ parameters for the filter with $\mathrm{c}=30 \mathrm{~mm}, \mathrm{~g}=25 \mathrm{~mm}$ and $\mathrm{d}=0.2 \mathrm{~mm}$ for second level iterated tree fractal tri-band filter (b) Measured S parameters of the filter with $\mathrm{c}=30 \mathrm{~mm}, \mathrm{~g}=28 \mathrm{~mm}$ and $\mathrm{d}=.2$ $\mathrm{mm}$ for third level iterated tree fractal tri-band filter.

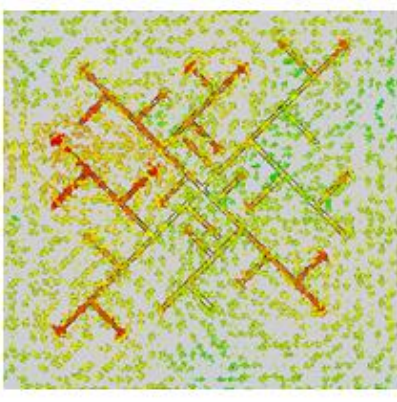

(a)

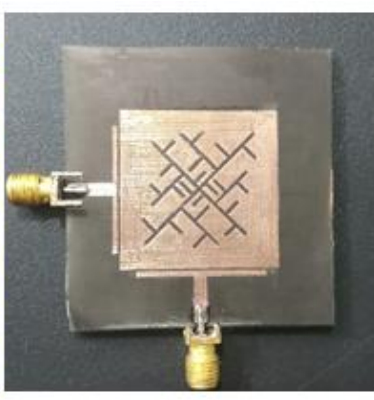

(b)

Figure 13. (a) Surface current distributions on the second level iterated tri-band filter at $4.6 \mathrm{GHz}$ (b) Prototype of the second level iterated tri-band filter.

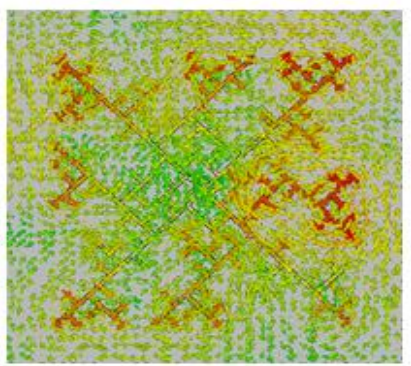

(a)

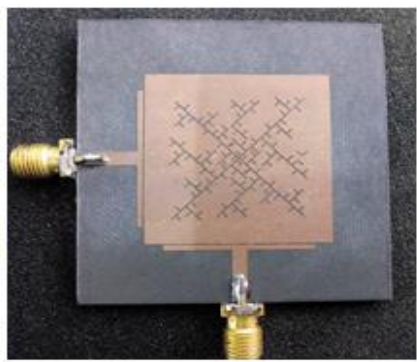

(b)

Figure 14. (a) Surface current distributions on the third level iterated tri-band filter at $4.7 \mathrm{GHz}$ (b) Prototype of the third level iterated tri-band filter. 
Table 3 gives the comparison of the proposed work with similar works reported. Not all fractal slotted structures on patches excites higher order modes.In [24] the third iteration Greek-cross fractal sections will give only a single pass band while the proposed work results in tripple pass bands. The increase in iteration level of the tree fractal slot shifts the resonant peaks to the lower frequency side, implies the property of miniaturization which is not obtained in [20], [24] and [27]. The proposed filter exhibits good insertion and return losses in the three pass bands in comparison to the other reported works.

Table 3. Comparison of proposed work with existing works

\begin{tabular}{|c|c|c|c|c|c|}
\hline$\overline{R e f}$ & $\begin{array}{c}\text { Fractal } \\
\text { Slot }\end{array}$ & $\begin{array}{c}\text { Iteration } \\
\text { Level }\end{array}$ & $\begin{array}{l}\text { Pass Band } \\
\text { Center Freq } \\
(\mathrm{GHz})\end{array}$ & $\begin{array}{l}\text { Side Length } \\
\text { of the patch } \\
(\mathrm{mm})\end{array}$ & $\begin{array}{c}\text { No of } \\
\text { Pass Bands }\end{array}$ \\
\hline \multicolumn{3}{|c|}{ [20] Trapezoidal Defection } & $3.73,6.72,10.2$ & 12 & Tripple \\
\hline [22] & Sierpinski & $2^{\text {nd }}$ & $5.4,9.05$ & 9 & Dual \\
\hline [24] & Greek-cross & $3^{\text {rd }}$ & 1.65 & 19.2 & Single \\
\hline [27] & Koch Fractal & $2^{\text {nd }}$ & 2.4 & 10.18 & Single \\
\hline This Work & Tree Fractal & $3^{\text {rd }}$ & $1.87,3.5,4.7$ & 28 & Tripple \\
\hline
\end{tabular}

\section{CONCLUSIONS}

A novel single square patch filter based on tree fractal slot is designed, analyzed and measured for dualmode, dual and tri-band responses. As otherwise needed for realizing multiband filters, the proposed multiband filter is simple without coupling gaps between various structures. The pass band frequency, transmission zeros and fractional bandwidths of the filter are controllable by varying the parameters $g$ and $d$ at various levels of tree fractal iterations for meeting the design requirements. The simulated and measured responses are in good agreement and the filter finds application in various wireless communication systems which fall in the frequency bands of GSM, Wi-Fi, WLAN, Wi-Max, Zigbee and Bluetooth.

\section{REFERENCES}

[1] Ralph Levy, R. V. Snyder, and George Matthaei, "Design of Microwave Filters", IEEE Transactions on Microwave Theory and Techniques, Vol.50, No.3, March 2002.

[2] D. M. Pozar, Microwave Engineering, John Wiley, 2000.

[3] R. N. Baral, P.K. Singhal, "Recent Techniques in Design and Implementation of Microwave Planar Filters", Radio Engineering, Vol.17, No. 4 December 2008.

[4] Jia-Sheng Hong and M. J. Lancaster, "Microstrip filters for RF/Microwave applications", John Wiley and sons, Inc, 2001.

[5] Lei Zhu, Pierre-Marie Wecowski, and $\mathrm{Ke} \mathrm{Wu}$, "New planar dual-mode filter using cross-slotted patch resonator for simultaneous size and loss reduction”, IEEE Transactions on Microwave Theory and Techniques, Vol.7, No.5, 650-64, May 1999.

[6] Lei Zhu, Boon Chai Tan, and Siang Juay Quek, "Miniaturized dual-mode bandpass filter using inductively loaded crossslotted patch resonator", IEEE Microwave \&Wireless Component Letters, Vol. No.1, 22-24, January 2005.

[7] Wen-Hua Tu and Kai Chang, "Miniaturized Dual-mode bandpass filter with harmonic control", IEEE Microwave and Wireless Components Letters, Vol. 1, No. 12,838- 840, December 2005.

[8] Adnan Gorur, "Description of coupling between degenerate modes of a dual mode microstrip loop resonator using a novel perturbation arrangement and its dual mode bandpass filter applications", IEEE Transactions on Microwave Theory and Techniques, Vol.52. No. 2,671-677, February 2004.

[9] Smain Amari, "Comments on description of coupling between degenerate modes of a dual mode microstrip loop resonator using a novel perturbation arrangement and its dual mode bandpass filter applications",IEEE Transactions on Microwave Theory and Techniques, Vol. 52. No. 9, 2190-2192, September 2004.

[10] S. Shen, R. Ramer, M. G. Banciu and R. R. Mansour, "Design and realization of star-geometry dual-mode bandpass filter", Optic Express, Vol.13, No.24, 9753-9758, November ,2005.

[11] Min-Hang Weng, Sean Wu, Shih-in Jhong,Yu-Chi Chang and Maw-Shung Lee, "A novel compact dual-mode filter using cross slotted patch resonator for dual band applns", Microwave Symposium, IEEE/MTT-S International, 9924, 2007, Doi: 10.1109/ MWSYM.2007.380131.

[12] K. S. K. Yeo and A. O. Nwajana, "A novel microstrip dual-band bandpass filter using dual mode square patch resonators", Progress in Electromagnetics Research C, Vol. 36, 233-247, January 2013.

[13] Sheng-Fuh Chang, Yng-Huey Jeng and Jia-Liang Chen, "Dual-band step-impedance bandpass filter for multimode wireless LANs", Electronic Letters, Vol.40, No.1,January 2004. 
[14] Sheng Su and Lei Zhu, "Compact Dual-Band Microstrip Bandpass Filter without External Feeds", IEEE Microwave and Wireless Components Letters, Vol. 15, No. 10, October 2005.

[15] Nurshamimi Rosli, et.al., "Design of compact multi-mode microstrip resonator filters for dual-band application", Indonesian Journal of Electrical Engineering and Computer Science Vol. 13, No. 2, February 2019, pp. 696-701.

[16] M. A. Sazali, N. A. Shairi, Z. Zakaria, "Hybrid Microstrip Diplexer Design for Multi-band WiMAX Application in 2.3 and 3.5 GHz Bands," International Journal of Electrical and Computer Engineering (IJECE) Vol. 8, No. 1, February 2018, pp. 576-584

[17] D. H.Werner and Suman Ganguly, “An overview of Fractal Antenna Engineeing Research”, IEEE Antennas and Propagation Magazine, Vol.45, No.1, February 2003.

[18] D. H. Werner and R. Mittra, Frontiers in Electromagnetics, Piscataway, NJ: IEEE Press, 2000, pp. 48-81.

[19] E. S.Ahmed, "Dual-Mode Dual-Band Microstrip Band pass Filter Based on Fourth Iteration T-Square fractal and Shorting Pin”, Radio Engineering, Vol. 21, No. 2, June 2012.

[20] Jian-Kang Xiao, Xiao-Peng Zu, Wei Zhao, and Jian Zhao, “Trapezoidal Patch Resonator Bandpass Filter," International Journal of Information and Computer Science, Volume 1, Issue 3, PP. 57-63, June 2012.

[21] Xu He-Xiu, Wang Guang-Ming, and Yang Zi-Mu, "Dual band left-handed metamaterials fabricated by using tree shape fractal", Chin. Phys. B, Vol. 21, No. 12, 2012.

[22] Y. S. Mezaal, H. T. Eyyuboğlu, J. K. Ali, "New Dual Band Dual-Mode Microstrip Patch Bandpass Filter Designs Based on Sierpinski Fractal Geometry", Proceeding of Advanced Computing and Communication Technologies, pp. 348-352, 2013

[23] K.G. Avinash, I. Srinivasa Rao, "Highly Selective Dual-Mode Microstrip Bandpass Filters Using Triangular Patch Resonators", Advanced Electromagnetics, Vol. 6, No. 1, March 2017.

[24] Hongshu Lu, Weiwei Wu, Jingiian Huang, Xiaofa Zhang, Naichang Yuan, "Compact Dual-mode Microstrip Bandpass Filter Based on Greek-cross Fractal Resonator", Radio Engineering, VOL. 26, NO. 1, April 2017.

[25] J. K. Ali and N. N. Hussain, "An Extra Reduced Size Dual-mode Bandpass Filter for Wireless Communication Systems", Progress In Electromagnetics Research Symposium Proceedings, Suzhou, China, September 2011.

[26] M. A. Alqaisy, J. K. Ali, C. K. Chakrabarty, and G. C. Hock1, "Design of a Compact Dual-mode Dual-band Microstrip Bandpass Filter Based on Semi-fractal CSRR", Progress In Electromagnetics Research Symposium Proceedings, Stockholm, Sweden, Aug, 2013.

[27] J. K. Ali, N. N. Hussain, A. J. Salim, and Hussam Alsaedi, “A New Tunable Dual-mode Bandpass Filter Design Based on Fractally Slotted Microstrip Patch Resonator", Progress In Electromagnetics Research Symposium Proceedings, KL, Malaysia, March 27-30, 2012, 1225-1228.

[28] Xu Liang and Michael Yan Wah Chia, "Multiband Characteristics of Two Fractal Antennas", Microwave and Optical Technology Letters / Vol. 23, No. 4, November 20, 1999.

[29] Benoit B. Mandelbrot, The fractal geometry of nature, New York: W. H. Freeman and Company, 1983

\section{BIOGRAPHIES OF AUTHORS}

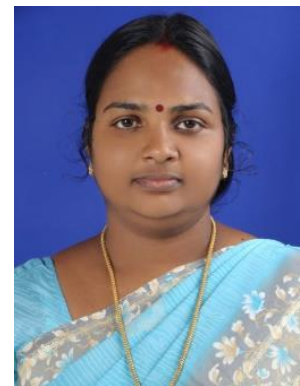

Manju Bhaskar was born on March 6th,1980 in Kochi, Kerala. She received her bachelor's degree in Electronics and Communication Engineering in 2001 from, School of Engineering, Cochin University of Science and Technolgy, Kochi, Kerala, and master's degree in Electronics and Communication with specialization in Optoelectronics and Optical communication from Department of Optoelectronics, Kerala University in 2008. She worked as faculty and Head of the Department of Electronics and Communication, KMEA Engineering College, Kochi, India from 2002 to 2018. She is a faculty of MGM College of Engineering and Technology, Kochi, India and is pursuing her research in Microwave Electronics at School of Technology \& Applied Sciences, Mahatma Gandhi Univerisity Regional Center, Edappally, Kochi. Her current areas of research includes RF/microwave filters for wireless and telecommunication applications.

Tel: (+91) 9495232324, Email: sudheeshmanju@gmail.com

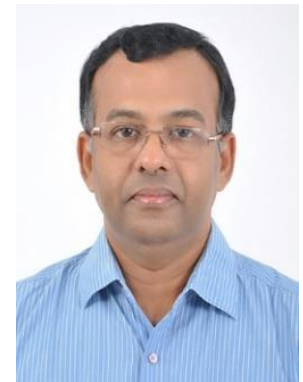

Dr.Thomaskutty Mathew received his Ph.D Degree in Microwave Electronics from Cochin University of Science and Technology Cochin, India in 1997. From 1995 to 1999 he worked as a Lecturer in Physics at Christ College, Irinjalakuda, India. Since 1999, he is working as faculty of the Department of Electronics, School of Technology \& Applied Sciences, Mahatma Gandhi University Regional Center, Edappally, Kochi, India and presently working as Reader in the Department. During the period 2006-2008, he worked as a Post Doctoral Research Associate at Department of Electronics, University of Kent, Canterbury, U.K. His current area of research activites are in Microstrip antennas, Radar Cross Section, RFID, Wireless Sensor Networks etc. $\mathrm{He}$ is a member of IEEE Antennas and propagation society and IET (U.K).

Tel: (+91) 90481 08856, E-mail: drtkmathew@gmail.com 